\title{
A New Hypothesis on the Strategy for Acquisition of Phosphorus in Arbuscular Mycorrhiza: Up-Regulation of Secreted Acid Phosphatase Gene in the Host Plant
}

\author{
Tatsuhiro Ezawa, ${ }^{1}$ Masahito Hayatsu, ${ }^{2}$ and Masanori Saito ${ }^{2}$ \\ ${ }^{1}$ Graduate School of Agriculture, Hokkaido University, Sapporo 060-8589, Japan; ${ }^{2}$ National Institute of Livestock and \\ Grassland Science, Nishi-nasuno, Tochigi 329-2793, Japan
}

Submitted 25 February 2005. Accepted 31 May 2005.

\begin{abstract}
The mycorrhiza-responsive phosphatase of Tagetes patula in symbiosis with Glomus etunicatum was detected by electrophoresis, was purified by column chromatography, and was characterized as acid phosphatase that was secreted into rhizosphere. The $\mathrm{N}$-terminal amino acid sequence was determined by a gas-phase sequencer, and a cDNA fragment of the phosphatase gene (TPPAP1) was amplified by degenerate primers designed based on the N-terminal amino acid sequence. The full-length cDNA was obtained by the rapid amplification of cDNA ends technique. The TpPAP1 was of host origin, and the cDNA was 1,843 bp long with a predicted open reading frame of polypeptide of 466 amino acids. Phylogenetic analysis revealed that the gene fell into the cluster of plant high-molecular-weight purple acid phosphatase. Expression analysis of the TpPAP1 in $T$. patula in symbiosis with Archaeospora leptoticha showed that the levels of transcripts increased eightfold by mycorrhizal colonization. Western blot analysis revealed that the 57-kDa protein corresponding to the mycorrhiza-responsive phosphatase increased by mycorrhizal colonization. The present study proposes a new strategy for acquisition of $P$ in arbuscular mycorrhizal associations in which the fungal partner activates a part of the low-P adaptation system of the plant partner, phosphatase secretion, and improves the overall efficiency of $P$ uptake.
\end{abstract}

Availability of phosphorus (P) in soil is relatively low in nature, i.e., $\mathrm{P}$ concentration in soil rarely exceeds $10 \mu \mathrm{M}$ (Bieleski 1973); thus, plant growth is likely limited by $P$. Plants have two strategies to adapt to a low-P environment: i) the enhancement of $\mathrm{P}$ uptake capability and ii) mobilization of inaccessible $\mathrm{P}$ such as sparingly soluble inorganic $\mathrm{P}$ and organic $\mathrm{P}$. The formation of symbiotic associations with arbuscular mycorrhizal (AM) fungi improves $\mathrm{P}$ uptake capability (Schachtman et al. 1998). In the association, the host plant supplies a carbon source to the fungal partner and the fungi construct an extraradical hyphal network that provides a huge

Corresponding author: T. Ezawa; E-mail: tatsu@ res.agr.hokudai.ac.jp

Current address for M. Hayatsu: Faculty of Agriculture, Shizuoka University, Shizuoka 422-8529, Japan.

Current address for M. Saito: Department of Environmental Chemistry, National Institute for Agro-Environmental Sciences, Tsukuba 305-8604, Japan.

The nucleotide sequence data for TpPAPI cDNA is available at the GenBank database under accession number AB029086. contact area between soil solution and host plant and enables the host plant to take up $\mathrm{P}$ far beyond the P-depletion zone around the roots. Expression of the high-affinity phosphate (Pi) transporter gene (Smith 2002) and a change in root architecture (Watt and Evans 1999; Williamson et al. 2001) are also typical responses of plants to enhance P uptake capability. It is known, however, that AM formation reduces expression levels of the high-affinity Pi-transporter gene of the host plant and the fungal Pi transporter on extraradical hyphae plays an alternative role in P uptake (Liu et al. 1998). To mobilize sparingly soluble Pi such as Al- and Fe-P, plants secrete low-molecularweight organic acid (Ryan et al. 2001). Secretion of acid phosphatase into the rhizosphere has been observed in many plants grown under P-deficient conditions and is considered to be involved in mineralization of organic $P$ (Duff et al. 1994). Secretion of acid phosphatase by AM fungi, on the other hand, is controversial. Tarafdar and Marschner (1994) observed an increase in phosphatase activity in the hyphosphere (hyphae-soil interface). Joner and Johansen (2000) also found extracellular phosphatase activity, but the enzyme was associated with the hyphal wall and was not secreted into the hyphosphere.

Phosphatase specific to mycorrhizal colonization was first found in the Allium cepa-Glomus mosseae association by an electrophoretic analysis and was characterized as alkaline phosphatase localized in the fungal vacuoles (Gianinazzi-Pearson and Gianinazzi 1976; Gianinazzi et al. 1979). The fungal alkaline phosphatase activity visualized by histochemical staining was employed as a biochemical index of active hyphae in terms of P nutrition (Boddington and Dodd 1999; Tisserant et al. 1993). However, subsequent detailed characterization of the enzyme suggested that the alkaline phosphatase was involved in fungal carbon metabolism (Ezawa et al. 1999). Furthermore, the gene expression analyses of GmALP and GiALP, alkaline phosphatase genes of Gigaspora margarita and Glomus intraradices, respectively, revealed that the expression levels of these genes were constitutive irrespective of the growth stages of both of the symbionts and external Pi concentration (Aono et al. 2004). Phosphatase specific to mycorrhizal colonization was also found in the Tagetes patula-AM fungal associations, and the activity correlated with the growth response of the plant partner to mycorrhizal formation under P-deficient conditions (Ezawa and Yoshida 1994a). This enzyme was purified and characterized as nonspecific acid phosphatase (EC 3.1.3.2) and was suggested to be of host origin (Ezawa and Yoshida 1994b). In this study, a gene encoding the mycorrhiza-responsive acid phosphatase was cloned, and the possible role of the enzyme in the P-acquisition strategy of the plant-fungal symbiotic system is discussed. 


\section{RESULTS}

Mycorrhiza-responsive acid phosphatase

in Tagetes patula is secreted into rhizosphere.

Dwarf marigold (Tagetes patula) was inoculated with Glomus etunicatum and was grown for 6 weeks in a growth chamber. The percentage of fungal colonization reached 40 to $45 \%$ at the time of harvest, while the control plants were uncolonized. Soluble enzyme was extracted from mycorrhizal and nonmycorrhizal roots and was subjected to electrophoresis, and acid phosphatase activity ( $\mathrm{pH}$ 5.0) was visualized on the gel. Activity of phosphatase corresponding to a relative mobility $\left(R_{\mathrm{m}}\right)$ of 0.12 increased in response to mycorrhizal colonization (Fig. 1A) that had been characterized as nonspecific acid phosphatase (E.C.3.1.3.2) (Ezawa and Yoshida $1994 \mathrm{~b})$. Low activity of phosphatase at the equivalent $R_{\mathrm{m}}$ was also observed in the nonmycorrhizal roots. The phosphatase showed a typical feature of secreted enzyme that could be extracted by $1 \mathrm{M} \mathrm{NaCl}$ without disruption of tissue (Fig. 1B). Secretion of the enzyme was inhibited by application of $1 \mathrm{mM}$

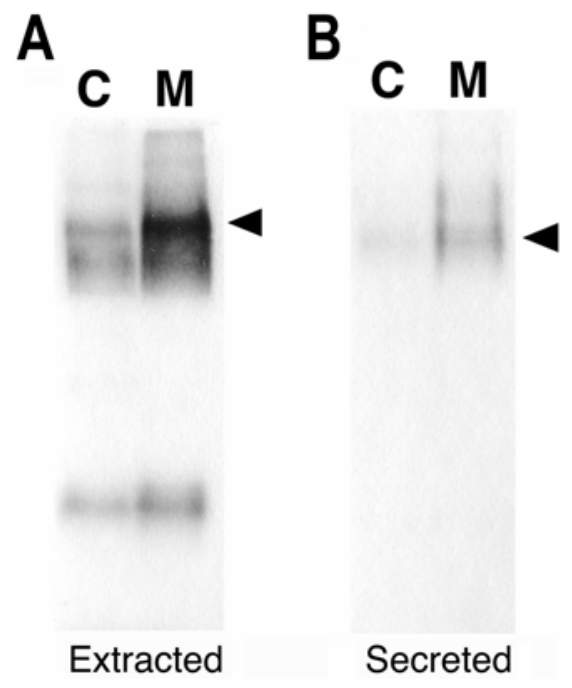

Fig. 1. Electrophoretic analysis of phosphatase in the roots of nonmycorrhizal Tagetes patula $(\mathrm{C})$ and Tagetes patula-Glomus etunicatum association (M). Phosphatase activity was visualized at $\mathrm{pH} 5.0$ by the azo-dye method. A, Crude extract was prepared from mycorrhizal and nonmycorrhizal roots, and $12.5 \mu \mathrm{g}$ protein was loaded on the gel. B, Intact mycorrhi$\mathrm{zal}$ and nonmycorrhizal roots were immersed in a 1:50 volume (wt/vol) of $1 \mathrm{M} \mathrm{NaCl}-50 \mathrm{mM}$ Tris $/ \mathrm{HCl}, \mathrm{pH} 7.5$, at $5^{\circ} \mathrm{C}$ for $4 \mathrm{~h}$, and $150 \mathrm{ng}$ protein was loaded on the gel after concentration by an ODS cartridge(Tosoh Corp.). Arrowheads indicate the mycorrhiza-responsive phosphatase $\left(R_{\mathrm{m}}=0.12\right)$. phosphate 1 week before harvest (data not shown). Denatured molecular weight of the phosphatase was estimated as $57 \mathrm{kDa}$, whereas the native molecular weight had been estimated as $102 \mathrm{kDa}$ (Ezawa and Yoshida 1994b).

\section{Isolation}

of a gene encoding the mycorrhiza-responsive phosphatase.

The mycorrhiza-responsive phosphatase was purified as described at Ezawa and Yoshida (1994b), and the N-terminal amino acid sequence was determined by a gas-phase sequencer as D-I-S-A-D-M-P-L-N-S-D-V-F-A-L. Degenerate primers for reverse-transcription-polymerase chain reaction (RTPCR) were designed based on the sequence. The nucleotide sequence and relative location of the PCR primers used in this study are shown in Table 1 and Figure 2, respectively. The first-strand cDNA was synthesized with the oligo (dT)T3-anchor primer, using mRNA prepared from the mycorrhizal roots. First and second (nested) PCR were performed with the degenerate primers and T3-anchor primer, and a 1.5kbp cDNA fragment (TpPAPl) was obtained, cloned, and sequenced. The $5^{\prime}$ end of the TPPAP1 was amplified by $5^{\prime}$ RACE (rapid amplification of cDNA end) technique, and the RACE fragment was cloned and sequenced. Subsequently, a full-length coding region of the TPPAPI cDNA was amplified by nested PCR with primer sets designed to the $5^{\prime}$ and $3^{\prime}$ end untranslated regions to confirm that the RACE fragment was from TpPAP1 mRNA. The full-length TpPAP1 cDNA was $1,843 \mathrm{bp}$ long with a predicted open reading frame of polypeptide of 466 amino acids (Fig. 3). The N-terminal polypeptide of 35 amino acids was rich in hydrophobic amino acids and a putative signal peptide. The sequence of 15 amino acids following the signal peptide was identical to

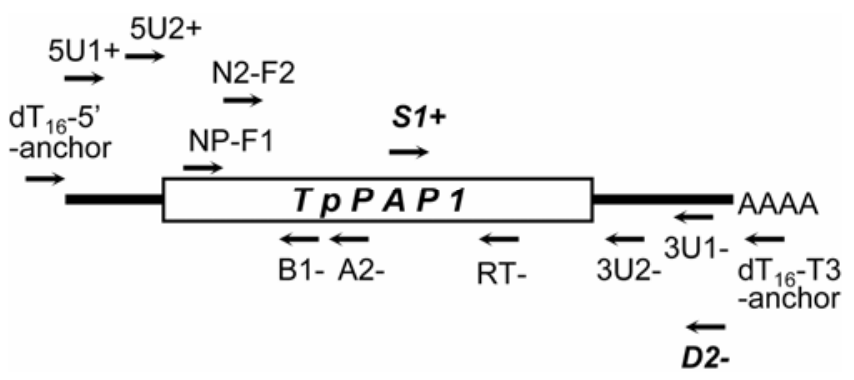

Fig. 2. Relative location of polymerase chain reaction primers used for amplification of TpPAP1 cDNA. An open box indicates the open reading frame. The italicized primers (S1+ and D2-) were employed for the assessment of TpPAP1 mRNA levels.

Table 1. Primers used for reverse transcription-polymerase chain reaction

\begin{tabular}{|c|c|c|c|}
\hline Name & Sequence $\left(5^{\prime}\right.$ to $\left.3^{\prime}\right)$ & Position in TpPAPI & Notes \\
\hline Oligo(dT)-T3-anchor & ATT AAC CCT CAC TAA AGG GA(T) $)_{16}$ & - & First strand cDNA synthesis for cloning \\
\hline T3-anchor & ATT AAC CCT CAC TAA AGG GA & - & First and 2nd primer for cloning \\
\hline NP-F1 & GAY ATH TCN GCN GAY ATG CC & 287 to 306 & First degenerate primer for cloning \\
\hline $\mathrm{N} 2-\mathrm{F} 2$ & CCN YTI AAY AGY GAY GTI TTY GC & 305 to 327 & Second degenerate primer for cloning \\
\hline RT- & CAT AAG CCG AGT AG & 1,027 to 1,040 & First-strand cDNA synthesis for $5^{\prime}$ RACE \\
\hline Oligo(dT)-5'-anchor & GAC CAC GCG TAT CGA TGT CGA C $(\mathrm{T})_{16} \mathrm{~V}$ & - & First sense primer for $5^{\prime}$ RACE \\
\hline A2- & CTC CTC TCC CTT CAT GAT CCC C & 374 to 395 & First antisense primer for $5^{\prime}$ RACE \\
\hline 5'-Anchor & GAC CAC GCG TAT CGA TGT CGA C & - & Second sense primer for $5^{\prime}$ RACE \\
\hline B1- & GGA GCA TTA AAG CCA TGA GG & 332 to 351 & Second antisense primer for $5^{\prime}$ RACE \\
\hline $5 \mathrm{U} 1+$ & TCC AAA CAC GCA AAC CAA GG & 100 to 119 & Sense primer for full-length cDNA \\
\hline $5 \mathrm{U} 2+$ & GAT CGC AAT AAC ATC TCC CC & 125 to 144 & Sense primer for full-length cDNA \\
\hline 3U1- & GCC CAT AGT TTA CAT CCA AC & 1,689 to 1,708 & Antisense primer for full-length cDNA \\
\hline $3 \mathrm{U} 2-$ & CTA TTC GTC CGT GGT ATT CG & 1,606 to 1,625 & Antisense primer for full-length cDNA \\
\hline $\mathrm{S} 1+$ & GGT GGG ATT CAT GGG CAA GG & 804 to 823 & Sense primer for TpPAP1 quantification \\
\hline D2- & CTC ATG CCC ATA GTT TAC ATC C & 1,692 to 1,713 & Antisense primer for TpPAP1 quantification \\
\hline NS1 & GTA GTC ATA TGC TTG TCT C & - & Sense primer for rDNA quantification \\
\hline NS21 & AAT ATA CGC TAT TGG AGC TGG & - & Antisense primer for rDNA quantification \\
\hline
\end{tabular}


that of N-terminal of the mature peptide determined by a gasphase sequencer. The predicted molecular mass of the mature peptide was $49.9 \mathrm{kDa}$.

\section{TpPAP1 is classified}

in the super family of purple acid phosphatase.

The deduced amino acid sequence of TPPAPl showed high similarity to plant purple acid phosphatases (PAP). The highest identity was observed with those of Ipomea batatas PAP2 (73\%), Glycine max PAP (69\%), and Nicotiana tabacum PAP19 (68\%). The phylogenetic analysis of the amino acid sequences of TpPAPl with other PAP from plants, fungi, and animals was carried out (Fig. 4). The TpPAP1 fell into the cluster of plant high-molecular-weight PAP (Schenk et al. 2000). Plant PAP are homodimeric Fe(III)-Zn(II) metalloenzymes (Durmus et al. 1999; Klabunde et al. 1996; Schenk et al. 2000; Sträter et al. 1995). Two motifs are involved in the $\mathrm{Fe}(\mathrm{III})-\mathrm{Zn}(\mathrm{II})$ binuclear metal center: motif A, DX $[\mathrm{G} / \mathrm{H}]$ $(\mathrm{X})_{\sim 25}-\mathrm{GDXX}[\mathrm{Y} / \mathrm{X}]_{\sim 25}-\mathrm{GNH}[\mathrm{E} / \mathrm{D}]$ and motif $\mathrm{B}, \mathrm{GH}-(\mathrm{X})_{\sim 50^{-}}$ GHXH. These motifs are conserved in TpPAP1 (Fig. 5). The cystein residue that was reported to form disulfide bond between monomers in red kidney bean (Phaseolus vulgaris) PAP existed in the equivalent position of TpPAP1.

Expression of TpPAP1 is up-regulated by mycorrhizal colonization and down-regulated by $\mathbf{P}$ fertilization.

The expression of TpPAP1 in response to AM formation was investigated by relative quantitative RT-PCR (Burleigh 2001). Marigold was inoculated with Archaeospora leptoticha and was grown for five weeks. The percentage of fungal coloniza- tion reached 35 to $40 \%$ at the time of harvest, while the control plants were uncolonized. Total RNA was extracted from the mycorrhizal and nonmycorrhizal roots, and first-strand cDNA was synthesized with both the oligo(dT) and NS21 primers, which targeted mRNA and $18 \mathrm{~S}$ ribosomal RNA, respectively (Table 1). The cDNA of TpPAPl and 18S ribosomal RNA were amplified with the primer sets of S1+/D2- and NS1/NS21, respectively, were Southern blotted, and were detected by digoxigenin (DIG)-labeled probes. At this stage, the TpPAPl was confirmed to be of host origin, because the 0.9-kbp fragment of TpPAPl could be amplified not only from mRNA extracted from the mycorrhizal roots but also from those of the nonmycorrhizal roots. Levels of TPPAPl transcripts were estimated by PCR kinetics and were standardized based on $18 \mathrm{~S}$ ribosomal RNA content, which was also determined by PCR kinetics (Fig. 6). The TpPAP1 transcripts increased in the mycorrhizal roots at an average of $8.3 \pm 3.7$ fold, compared with those in the nonmycorrhizal controls (Table 2). The TpPAP1 transcripts were not detectable in the mycorrhizal plants nor nonmycorrhizal plants fertilized with $1 \mathrm{mM}$ phosphate $24 \mathrm{~h}$ prior to harvest (data not shown).

\section{Western blot analysis of $T$ pPAP1 product.}

To raise an antiserum against the $T P P A P 1$ product, synthetic peptide (YP-337) corresponding to the first 20 residues of the $\mathrm{N}$ terminal of the mature peptide was employed as an immunogen. Two rabbits were immunized with YP-337 and antiserum showing higher titer was used for the subsequent Western blotting analysis. T. patula was inoculated with Archaeospora leptoticha and was grown for six weeks, and crude extracts were prepared from mycorrhizal and nonmycorrhizal roots. Protein
1

101

201

301

401

501

601

701

801

901

1001

1101

1201

1301

1401

1501

1601

1701

1801

caacatataa ctatcttatt attattaaga gcaaatacag gtcctccact ccaatccacc taatctaatc cagccaataa tcacaatcat aacactttat $M A M \quad G \quad L \quad G \quad L$ ccaaacacgc aaaccaaggt cagcgatcgc aataacatct cccctgccta ctgcaattac agttcagata aacatccatc tatggccatg ggattgggat $\begin{array}{lllllllllllllllllllllllllllllllll}G & S & V & Y & L & L & L & L & C & F & V & L & T & S & C & C & N & G & G & I & S & S & S & Y & S & R & T & N & D & I & S & A & D\end{array}$ tgggatcagt ttatctgttg ttactgtgtt tcgttctcac atcctgctgc aatggaggga tcagtagcag ttattcaaga accaatgaca tcagtgctga

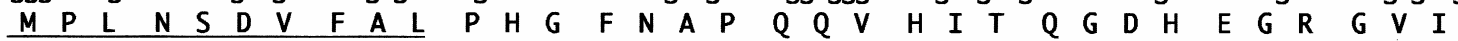
tatgccatta aacagcgatg tttttgcact tcctcatggc tttaatgctc ctcaacaggt tcacataaca caaggggatc atgaagggag aggagtaatt

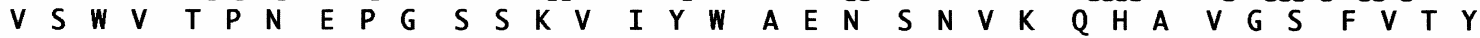
gtttcttggg tcacaccaaa tgaacctggt tcaagtaaag taatttactg ggccgagaat agcaacgtca aacaacacgc agtgggatct tttgtcacct $\begin{array}{llllllllllllllllllllllllllllllllll}K & Y & Y & N & Y & S & S & P & Y & I & H & H & C & T & I & K & N & L & E & Y & N & T & K & Y & F & Y & E & L & G & T & G & N & V\end{array}$ acaagtacta caactacagc tcaccgtaca tccatcattg caccatcaag aatcttgaat ataataccaa gtatttttac gagcttggga caggcaacgt $\begin{array}{llllllllllllllllllllllllllllllllll}T & R & Q & F & W & F & T & T & P & P & E & V & G & P & D & V & P & Y & T & F & G & L & I & G & D & L & G & Q & T & F & D & S & N\end{array}$ cacacgacag ttttggttta ccacacctcc tgaagttggc cctgatgttc cttatacttt tggtcttatc ggggatcttg gtcaaacatt tgactccaac $\begin{array}{llllllllllllllllllllllllllllllllll}R & T & L & T & H & Y & E & S & N & P & A & K & G & Q & A & V & L & F & V & G & D & L & S & Y & A & D & A & Y & P & L & H & D & N & N\end{array}$ cgaactttga ctcattatga gtcaaaccca gcaaaagggc aggcagtgct ttttgttggt gacctttcgt atgcagatgc gtacccgttg catgataata

$\begin{array}{lllllllllllllllllllllllllllllllll}R & \text { W } & D & S & \text { W } & A & R & F & V & E & R & S & V & A & Y & Q & P & W & I & W & S & A & G & N & H & E & I & D & Y & L & P & E & Y\end{array}$ ataggtggga ttcatgggca aggtttgtag aaagaagcgt ggcttaccaa ccatggattt ggagtgctgg gaatcatgaa attgattacc ttcctgaata $\begin{array}{llllllllllllllllllllllllllllllllll}G & E & G & E & P & F & K & P & Y & T & H & R & Y & Y & V & P & Y & E & A & P & G & V & H & L & R & F & G & Y & S & I & K & R & A\end{array}$ tggtgaaggt gaaccattta agccttatac acatcggtat tatgtgccat atgaagcacc gggagtacat ctccgctttg ggtactcgat taaaagagct $\begin{array}{lllllllllllllllllllllllllllllllllll}S & A & Y & I & I & V & M & S & S & Y & S & A & Y & G & M & Y & T & P & Q & Y & K & W & L & M & N & E & L & P & K & V & N & R & S & E\end{array}$ tctgcttaca taatcgtgat gtcatcctac tcggcttatg gaatgtacac gcctcaatat aaatggctca tgaacgagct accaaaggtt aaccgaagcg

$\begin{array}{lllllllllllllllllllllllllllllllll}T & P & W & L & I & V & V & M & H & C & P & L & Y & S & T & Y & L & H & H & Y & M & E & G & E & T & M & R & V & M & Y & E & Q & Y\end{array}$ agacaccatg gttaattgtg gttatgcact gtccattata tagtacctat ttgcatcatt atatggaagg tgaaacaatg agagtgatgt atgaacaata $\begin{array}{llllllllllllllllllllllllllllllllll} & F & V & K & Y & K & V & D & V & V & F & S & G & H & V & H & A & Y & E & R & T & E & R & I & S & N & V & A & Y & N & I & E & N & G\end{array}$ ttttgttaag tataaagttg atgtcgtgtt ttctggacat gttcatgcct atgagcgaac ggaacggata tcaaatgttg cttacaatat cgaaaacgga $\begin{array}{lllllllllllllllllllllllllllllllllll}L & C & T & P & R & N & D & E & Y & A & P & V & Y & I & T & I & G & D & G & G & N & Q & E & G & L & L & Y & E & M & V & D & P & Q & P\end{array}$ ttgtgcactc ctagaaatga cgaatatgcc cccgtttaca ttaccattgg tgatggtgga aaccaagaag gattgctata tgagatggta gatccacagc

$\begin{array}{llllllllllllllllllllllllllllllllll}K & Y & S & A & F & R & E & P & S & Y & G & H & A & T & F & E & I & K & N & R & T & T & A & Y & Y & A & W & H & R & N & Q & D & G\end{array}$ ctaagtattc agcatttagg gaaccgagct acgggcatgc tacatttgag atcaagaaca gaactactgc ttactatgct tggcatcgta atcaagatgg

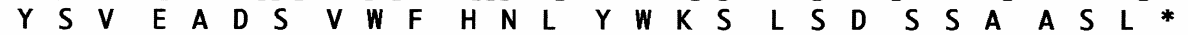
gtattctgtt gaagccgatt ccgtatggtt tcacaatttg tactggaaat cattgtcaga ttcatctgct gcatctttgt gagtcgaaat tcaagattat acgtccgaat accacggacg aataggttcc tcagctgcat cacaagattc atgatgttga ccttgataac tttttattct tagatcatgt tggatgtaaa ctatgggcat gagattgata tctacagatg tattttacaa tcagtaaaat gttgtagaat atactgtttg gatgtgttat ctgtatttga tcttaataat aataagatag ttaaatgttg aagtgttaaa aaaaaaaaaa aaa

Fig. 3. Nucleotide and deduced amino acid sequences of TpPAP1. The first 35 amino acids (italicized) are a putative signal peptide, followed by an identical sequence of the mature peptide of mycorrhiza-responsive phosphatase determined by a gas-phase protein sequencer (underlined). 
$(30 \mu \mathrm{g})$ was subjected to sodium dodecyl sulfate-polyacrylamide gel electrophoresis (SDS-PAGE) and was electroblotted onto a nitrocellulose membrane. Immunodetection was carried out with the ECL Western blotting detection system according to the manufacturer's instructions. The antiserum reacted with the $57-\mathrm{kDa}$ protein that corresponded to the mycorrhiza-responsive phosphatase (Fig. 7). More intensive signal was observed in the mycorrhizal roots than in the nonmycorrhizal roots.

\section{DISCUSSION}

The following evidence confirmed that the TpPAP1 encodes the mycorrhiza-responsive acid phosphatase in T. patula: i) the $\mathrm{N}$-terminal amino acid sequence following the putative signal peptide in the predicted open reading frame of $T p P A P l$ was identical to that of the mycorrhiza-responsive phosphatase determined by a gas-phase sequencer, ii) deduced amino acid sequence of the TPPAPl showed highest similarity to those of other plant acid phosphatases, iii) the transcript levels of $T p P A P 1$ increased in response to AM formation, and iv) the antiserum against the synthetic peptide, designed based on the N-terminal amino acid sequence of TPPAP1 mature polypeptide, reacted with the $57-\mathrm{kDa}$ protein that corresponded to the mycorrhiza-responsive acid phosphatase. The TpPAPl was further classified in the super family of PAP in which the metallo-phosphoesterase motifs were conserved. The native and denatured molecular mass of the mycorrhiza-responsive phosphatase suggests that the enzyme is functioning as a homodimer, which would be linked by a disulfide bond between the cystein residue conserved in the TpPAP1, as those found in other PAP (Schenk et al. 2000).

The gene expression of plant PAP is regulated by $\mathrm{P}$ nutrition. The transcription levels of PAP increased in response to $\mathrm{P}$ deficiency and decreased under P-sufficient conditions (Haran et al. 2000; Li et al. 2002; Miller et al. 2001; Nishikoori et al. 2001). Generally, AM formation improves $P$ nutrition, and this may result in decrease in PAP gene expression in theory. In

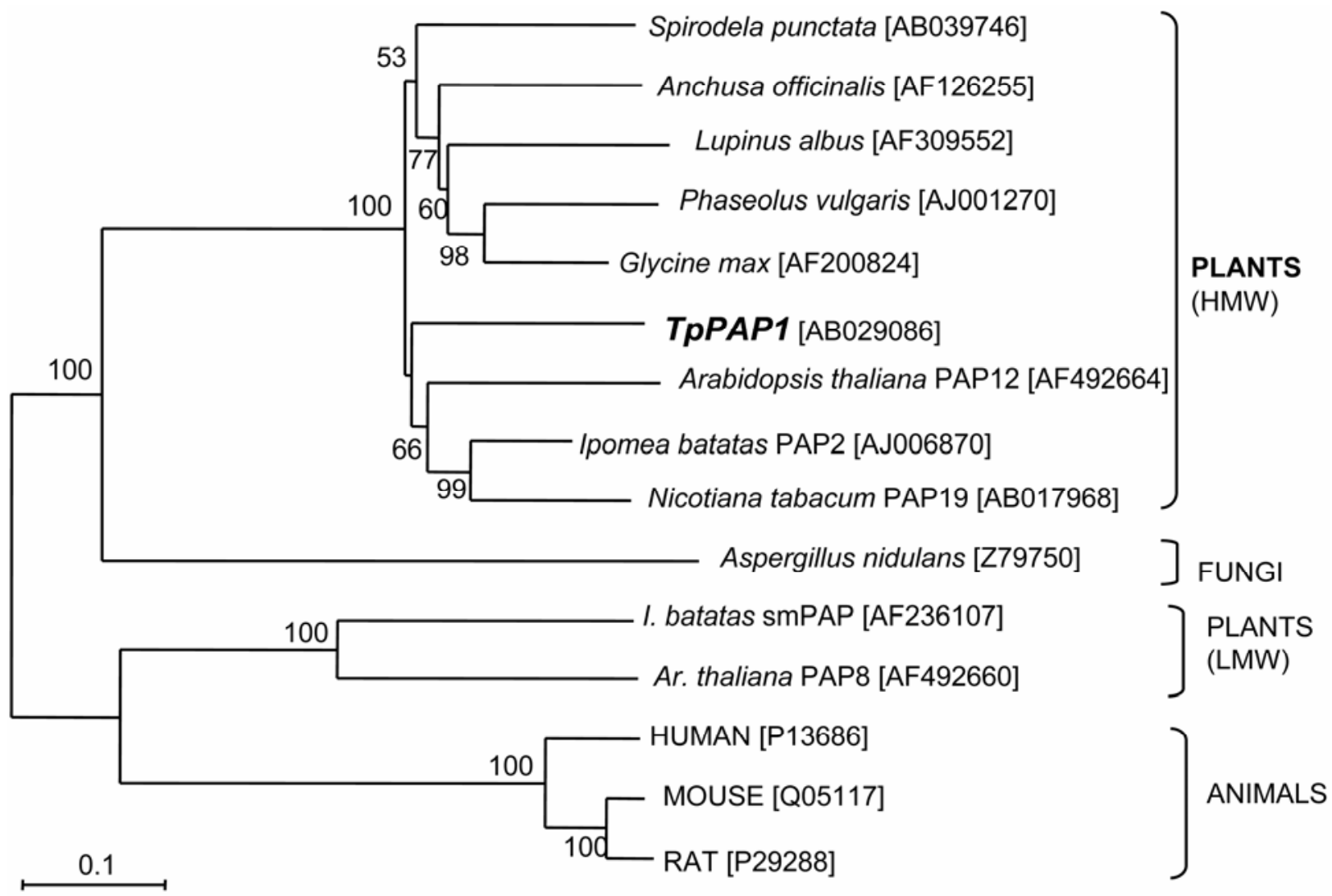

Fig. 4. Phylogenetic analysis of purple acid phosphatases (PAP) of plants, fungi, and animals. The deduced amino acid sequences were aligned using ClustralW, and the phylogenetic tree was drawn by the neighbor-joining method. Bootstrap values are shown at the nodes as a percentage of 1,000 replications. GenBank accession numbers are indicated. HMW = plant high molecular weight PAP, LMW = plant low molecular weight PAP.
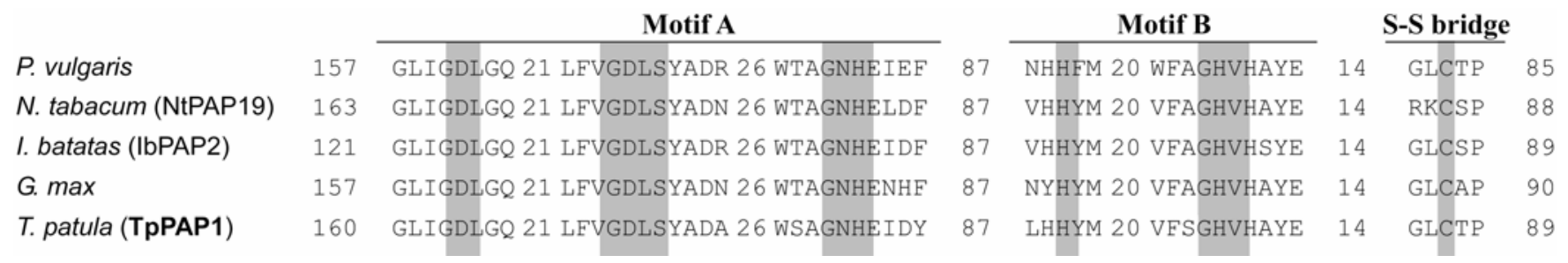

Fig. 5. Partial alignment of the deduced amino acid sequences of plant purple acid phosphatases (PAP). The GenBank accession numbers are: Nicotiana tabacum PAP19, AB017968; Ipomea batatas PAP2, AJ006870; Glycin max PAP, AF200824; Tagetes patula TpPAP1 (this study), AB029086. Motifs A and B are the metallo-phosphoesterase domains, and the S-S bridge is the cystein residue forming a disulfide bond between the monomers. The numbers indicate the number of amino acid residues before, between, and following the regions. The conserved residues are indicated with shading. 
fact, the expression of the Medicago truncatula PAP gene probed by one of the Arabidopsis PAP cDNAs decreased by AM formation (Liu et al. 1998). However, it has been known that several plants, Triticum aestivum, Allium cepa (Dodd et al. 1987), Zea mays (Fries et al. 1998), and Tagetes patula (Ezawa and Yoshida 1994a), increased acid phosphatase activity in roots in response to AM formation. The present study revealed that the increase in acid phosphatase activity in the T. patula$\mathrm{AM}$ association was regulated at the gene expression levels. Plants possess several PAP genes in genome (Durmus et al. 1999; Kaida et al. 2003; Li et al. 2002), and the expressions of these genes are differently regulated (Kaida et al. 2003; Li et al. 2002). It is postulated that plants, including M. truncatula, have an isoform of PAP that would respond to AM formation. Further investigation is required to confirm this hypothesis.

The role of secretory acid phosphatase has not yet been well defined. It is considered, however, that the most probable function is hydrolyzation of organic $\mathrm{P}$ present in rhizosphere to release $\mathrm{Pi}$, which could be taken up by the roots (Duff et al. 1994). A wide range of plant species secretes acid phosphatase into rhizosphere under P-deficient conditions irrespective of mycotrophic status. Lupinus albus secretes substantial amounts of acid phosphatase from proteoid (cluster) roots formed under P stress (Miller et al. 2001; Wasaki et al. 1999). Since L. albus does not form mycorrhiza, the secretion of acid phosphatase is regarded as an important part of $\mathrm{P}$ acquisition strategies of nonmycorrhizal plants. Secretion of acid phosphatase could be beneficial also for mycotrophic plants, especially for those associated with the AM fungi developing a hyphal network relatively close to the roots, such as Scutellospora calospora (Smith et al. 2000). The promotion of PAP gene expression

\section{[TpPAP1 mRNA]}

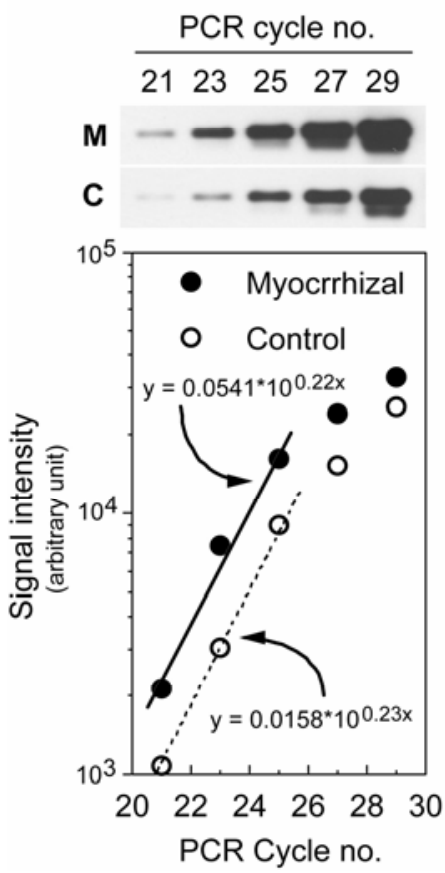

[18S rRNA]

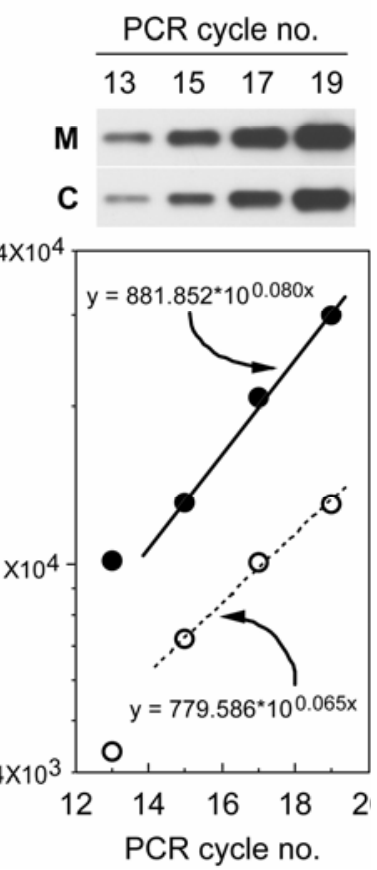

Fig. 6. Quantification of TpPAP1 mRNA in the roots of nonmycorrhizal Tagetes patula (Control) and T. patula-Archaeospora leptoticha association (Mycorrhizal) by reverse transcription-polymerase chain reaction (PCR). The TpPAP1 mRNA and 18S rRNA (constitutive control) were reverse-transcribed, amplified, electrophoresed, transferred onto a nylon membrane, and detected by the digoxigenin-labeled probes. Signal intensity of the Southern hybridization was quantified by image analysis, and the intensity versus cycle number of the PCR was plotted. The levels of the cDNA template in the PCR were estimated by the regression equations determined by the linear portions of the PCR kinetics. and the subsequent secretion of PAP by AM formation would accelerate mineralization of organic $\mathrm{P}$ in the rhizosphere, resulting in the enhancement of $\mathrm{P}$ uptake through the extraradical hyphae as well as through the roots.

Another function of extracellular phosphatase, proposed by Barrett-Lennard and associates (1993), is salvaging P esters leaked from the root cell. Plant roots exude various organic compounds such as sugar and organic acid, especially under nutrient-deficient conditions (Dakora and Phillips 2002). In addition, AM formation altered membrane permeability of the root cell to provide a carbon source for the fungal partner, e.g., the up-regulation of sugar transporter gene (Harrison 1996). It is likely that $\mathrm{P}$ esters also leak from the root cell and that the PAP hydrolyzes those compounds for P recycling.

The $\mathrm{P}$ acquisition mechanism of mycorrhizal plants has been well documented. The establishment of mycorrhizal association enables $\mathrm{P}$ uptake through the hyphal network extended beyond the P-depletion zone around the roots (Schachtman et al. 1998). The present study, however, proposes a new mechanism that the fungal partner activates a part of the low-P adaptation system of the plant partner, PAP secretion, and improves the overall efficiency of $\mathrm{P}$ uptake. The molecular mechanism involved in this interaction is of interest and remains to be clarified.

Table 2. Influence of mycorrhizal formation (Archaeospora leptoticha) of Tagetes patula on TpPAP1 transcription levels ${ }^{\mathrm{a}}$

\begin{tabular}{lccc}
\hline & \multicolumn{3}{c}{ Levels of TpPAP1 transcripts } \\
\cline { 2 - 4 } Tissue & Replication 1 & Replication 2 & Replication 3 $^{\mathbf{b}}$ \\
\hline Mycorrhizal (M) & 0.0294 & 0.0541 & 0.1450 \\
Control (C) & 0.0049 & 0.0158 & 0.0094 \\
M/C (fold) & 6.0 & 3.4 & 15.5 \\
Average (fold \pm SE) & & $8.3 \pm 3.7$ & \\
\hline
\end{tabular}

${ }^{a}$ As revealed by quantitative reverse transcription-polymerase chain reaction. Measurement in arbitrary units.

b The transcription levels of TpPAP1 were standardized by the amount of $18 \mathrm{~S}$ rRNA.

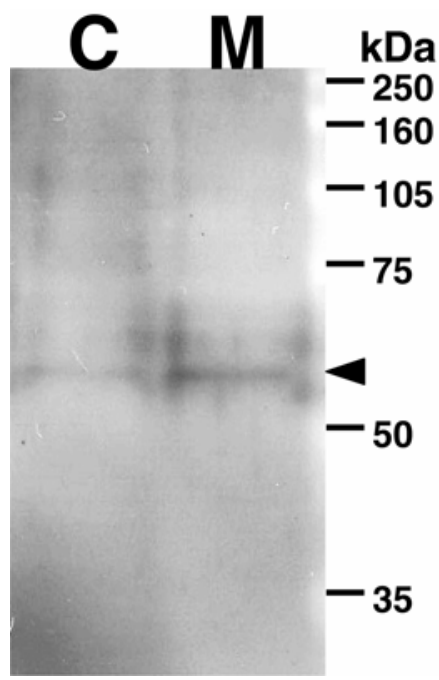

Fig. 7. Western blot analysis of TPPAP1 product in the roots of nonmycorrhizal Tagetes patula (C) and Tagetes patula-Archaeospora leptoticha association (M). Crude extract was prepared from the mycorrhizal and nonmycorrhizal roots, and $30 \mu \mathrm{g}$ protein was electrophoresed on a sodium dodecyl sulfate-polyacrylamide gel and was electroblotted onto a nitrocellulose membrane. The membrane was reacted with a rabbit antiserum against the synthetic peptide corresponding to the first 20 residues of the N-terminal of mature TPPAP1 protein and was detected by secondary antibody with the chemiluminescent detection system. 


\section{MATERIALS AND METHODS}

\section{Plant and fungal materials.}

Dwarf marigold (T. patula cv. Bonanza Orange) was inoculated with $1 \mathrm{ml}$ of a spore/water suspension $\left(200\right.$ spores $\left.\mathrm{ml}^{-1}\right)$ of Glomus etunicatum (isolated by T. Wood, NPI, Salt Lake City, UT, U.S.A., for protein purification and gene isolation) or with Archaeospora leptoticha (strain OK-15, MAFF 520072, for gene expression analysis and Western blot) and was grown on river sand (for Glomus etunicatum) or a 9:1 sand/soil ( $\mathrm{pH}$ 4.9, available phosphate was less than $1.0 \mathrm{mg} \mathrm{kg}^{-1}$ ) mixture (for Archaeospora leptoticha) in a growth chamber (16-h photoperiod, $25^{\circ} \mathrm{C}$ ). The spore/water suspension was passed through a $53-\mu \mathrm{m}$ sieve and was used as the mock inoculum for the nonmycorrhizal controls. The plants received liquid fertilizer $\left(4 \mathrm{mM} \mathrm{NH} \mathrm{NO}_{3}, 1 \mathrm{mM} \mathrm{K} \mathrm{SO}_{4}, 0.75 \mathrm{mM} \mathrm{MgSO}_{4}, 2 \mathrm{mM}\right.$ $\mathrm{CaCl}_{2}, 0.5 \mathrm{mM}$ Fe-EDTA, $50 \mu \mathrm{M} \mathrm{KH}_{2} \mathrm{PO}_{4}$ ) two to three times per week in sufficient amounts, until the solution flowed out from the drain holes. After five weeks, the plants were harvested and the roots were washed on a 500- $\mu \mathrm{m}$ mesh, were wiped with a paper towel, were weighed and frozen in liquid nitrogen, and were stored at $-80^{\circ} \mathrm{C}$.

\section{Electrophoretic analysis of phosphatase.}

Roots (500 to $700 \mathrm{mg}$ fresh weight) were ground on a mortar at $0^{\circ} \mathrm{C}$ with an equal volume (wt/vol) of $5 \mathrm{mM}$ ascorbate, $2 \%$ (wt/vol) polyvinylpryrolidone in $100 \mathrm{mM}$ borate buffer $(\mathrm{pH}$ 8.8) and an equal weight of sea sand. The slurry was transferred to a $1.5-\mathrm{ml}$ tube and was centrifuged at $15,000 \times g$ for 5 $\min$ at $4{ }^{\circ} \mathrm{C}$, and the supernatant was transferred to a new tube and was subjected to electrophoresis.

Secreted enzyme was prepared from intact roots. The mycorrhizal and nonmycorrhizal roots were harvested and gently washed in water, were blotted on a paper towel, were weighed, and were immersed in a 1:50 volume (wt/vol) of $1 \mathrm{M} \mathrm{NaCl}$ in $50 \mathrm{mM}$ Tris/ $\mathrm{HCl}$ buffer $(\mathrm{pH} 7.5)$ at $5^{\circ} \mathrm{C}$ with slow stirring. After $4 \mathrm{~h}$, the roots were removed, and the solution was centrifuged at $1,500 \times g$ for $5 \mathrm{~min}$. Solid ammonium sulfate was added to the supernatant to $80 \%$ saturation, and then, the solution was introduced onto the Toyopak ODS-S cartridge (Tosoh Corp., Tokyo). Adsorbed protein was eluted with $1.5 \mathrm{ml}$ of $100 \mathrm{mM}$ Tris/citrate buffer ( $\mathrm{pH}$ 7.5) and was subjected to electrophoresis.

Protein concentration in the enzyme solutions was determined by the $D C$ protein assay (Bio-Rad Laboratories, Hercules, CA, U.S.A.), using bovine serum albumin as a standard. The enzyme solutions were loaded on a 10\% SDS-polyacrylamide gel without denaturing (Ezawa and Yoshida 1994a). Phosphatase activity on the gel was visualized by the azo dye method (Scandalios 1969). Molecular weight of the denatured protein was estimated by relative mobility to the protein standards on a $10 \%$ SDS-polyacrylamide gel.

\section{Cloning of the TPPAP1.}

Acid phosphatase specific to arbuscular mycorrhizal colonization in marigold was purified as described by Ezawa and Yoshida (1994b), was electrophoresed on a 10\% SDS-polyacrylamide gel, and was blotted on a polyvinylidene diflouride membrane. The N-terminal amino acid sequence of the protein was determined by a gas-phase protein sequencer (ABI 476A, Applied Biosystems, Foster City, CA, U.S.A.). The degenerate primers for RT-PCR were designed based on the sequence.

Roots $(500$ to $700 \mathrm{mg}$ ) were ground in a mortar with liquid nitrogen, and total RNA was extracted and purified with the RNeasy plant mini kit (Qiagen, Valencia, CA, U.S.A.). Poly $(\mathrm{A})^{+}$RNA was prepared with the mRNA isolation kit (Roche Diagnostics, Mannheim, Germany), according to the manufacturer's instructions. First-strand cDNA was synthe- sized with the First-strand cDNA synthesis kit for RT-PCR (Roche Diagnostics), using the oligo (dT)-T3-anchor primer (Table 1). The High-fidelity expand PCR system (Roche Diagnostics) was employed for PCR amplification. The first PCR was performed with the sense-degenerate primer NP-F1 (5 $\mu \mathrm{M})$ and the T3-anchor primer $(0.3 \mu \mathrm{M})$, using the 1- $\mu \mathrm{l}$ cDNA template in a total volume of $50 \mu$ l. The amplification cycles were as follows: initial denaturation at $94^{\circ} \mathrm{C}$ for $2 \mathrm{~min}$, followed by 30 cycles of $94^{\circ} \mathrm{C}$ for $30 \mathrm{~s}, 52^{\circ} \mathrm{C}$ for $1 \mathrm{~min}, 72^{\circ} \mathrm{C}$ for $1 \mathrm{~min}$, plus cycle elongation of $15 \mathrm{~s}$ for each cycle, with a final extension at $72^{\circ} \mathrm{C}$ for $10 \mathrm{~min}$. The second (nested) PCR was done with the sense-degenerate primer N2-F2 $(5 \mu \mathrm{M})$ and the $0.3-\mu \mathrm{M}$ T3-anchor primer, using the $0.5-\mu \mathrm{l} \mathrm{PCR}$ product of the first PCR in a total volume of $50 \mu$. The amplification cycles of the second PCR were as follows: initial denaturation at $94^{\circ} \mathrm{C}$ for $2 \mathrm{~min}$, followed by 30 cycles of $94^{\circ} \mathrm{C}$ for $30 \mathrm{~s}, 49^{\circ} \mathrm{C}$ for $1 \mathrm{~min}, 72^{\circ} \mathrm{C}$ for $1 \mathrm{~min}$, plus cycle elongation of $15 \mathrm{~s}$ for each cycle, with a final extension at $72^{\circ} \mathrm{C}$ for $10 \mathrm{~min}$. The 1.5 kbp cDNA fragment of the second PCR was cloned into the pUC119 plasmid vector (Takara Bio Inc., Shiga, Japan) and was sequenced with the ABI Prism 373A sequencer (Applied Biosystems).

The $5^{\prime}$ end of the cDNA was amplified with the $5^{\prime} / 3^{\prime}$ RACE kit (Roche Diagnostics). Poly(A) ${ }^{+}$RNA was prepared from total RNA as described above, and first-strand cDNA was synthesized using the antisense primer RT-. After homopolymeric dA-tailing to the $3^{\prime}$ end of the cDNA, PCR amplification was performed with the oligo(dT)-5'-anchor primer $(0.75 \mu \mathrm{M})$ and the antisense primer $\mathrm{A} 2-(0.25 \mu \mathrm{M})$, using $2.5 \mu \mathrm{l}$ of cDNA template in a total volume of $25 \mu \mathrm{l}$. The amplification cycles were as follows: initial denaturation at $94^{\circ} \mathrm{C}$ for $2 \mathrm{~min}$, followed by 10 cycles of $94^{\circ} \mathrm{C}$ for $15 \mathrm{~s}, 60^{\circ} \mathrm{C}$ for $30 \mathrm{~s}, 72^{\circ} \mathrm{C}$ for $40 \mathrm{~s}, 25$ cycles of $94^{\circ} \mathrm{C}$ for $15 \mathrm{~s}, 60^{\circ} \mathrm{C}$ for $30 \mathrm{~s}, 72^{\circ} \mathrm{C}$ for $40 \mathrm{~s}$, plus cycle elongation of $20 \mathrm{~s}$ for each cycle, with a final extension at $72^{\circ} \mathrm{C}$ for $7 \mathrm{~min}$. The second (nested) PCR was done with the $5^{\prime}$-anchor primer $(0.75 \mu \mathrm{M})$ and the antisense primer B1- $(0.25 \mu \mathrm{M})$, using $0.05 \mu \mathrm{l}$ of the first PCR product in a total volume of $25 \mu$. The amplification cycles of the second PCR were as follows: initial denaturation at $94^{\circ} \mathrm{C}$ for $2 \mathrm{~min}$, followed by 10 cycles of $94^{\circ} \mathrm{C}$ for $15 \mathrm{~s}, 57^{\circ} \mathrm{C}$ for $30 \mathrm{~s}, 72^{\circ} \mathrm{C}$ for $40 \mathrm{~s}, 25$ cycles of $94^{\circ} \mathrm{C}$ for $15 \mathrm{~s}$, $57^{\circ} \mathrm{C}$ for $30 \mathrm{~s}, 72^{\circ} \mathrm{C}$ for $40 \mathrm{~s}$, plus cycle elongation of $20 \mathrm{~s}$ for each cycle, with a final extension at $72^{\circ} \mathrm{C}$ for $7 \mathrm{~min}$. The product of the second PCR was cloned into the pT7Blue-2 plasmid vector (Novagen, Madison, WI, U.S.A.) and was sequenced with the ABI Prism 3100 sequencer (Applied Biosystems).

To assure that the RACE fragment was originated from the $T p P A P 1$ cDNA, full-length of the coding region of TpPAPl cDNA was amplified by using the $5 \mathrm{U} 1+, 5 \mathrm{U} 2+, 3 \mathrm{U} 1-$, and $3 \mathrm{U} 2$ - primers, which were located in the $5^{\prime}$ and $3^{\prime}$ untranslated regions of the TpPAPI cDNA. Poly(A)+ RNA was prepared as described above, and the first-strand cDNA was synthesized using the oligo $(\mathrm{dT})_{15}$ primer. The first PCR amplification was performed with the sense primer $5 \mathrm{U} 1+(0.2 \mu \mathrm{M})$ and the antisense primer $3 \mathrm{U} 1-(0.2 \mu \mathrm{M})$, using $2.5 \mu \mathrm{l}$ of cDNA template in a total volume of $25 \mu \mathrm{l}$. The amplification cycles were as follows: initial denaturation at $94^{\circ} \mathrm{C}$ for $2 \mathrm{~min}$, followed by 30 cycles of $94^{\circ} \mathrm{C}$ for $30 \mathrm{~s}, 53^{\circ} \mathrm{C}$ for $50 \mathrm{~s}$, and $72^{\circ} \mathrm{C}$ for $1 \mathrm{~min}$, with a final extension at $72^{\circ} \mathrm{C}$ for $5 \mathrm{~min}$. The second (nested) PCR was done with either the primer set of $5 \mathrm{U} 1+$ and $3 \mathrm{U} 2-$ $(0.2 \mu \mathrm{M}$, respectively) or that of $5 \mathrm{U} 2+$ and $3 \mathrm{U} 1-(0.2 \mu \mathrm{M}$, respectively), using the $0.025 \mu \mathrm{l}$ of the first PCR product in a total volume of $25 \mu \mathrm{l}$. The amplification cycles of the second PCR were the same as those of first PCR. The products of the second PCR were cloned into the pT7Blue-2 plasmid vector (Novagen) and were sequenced. 
Quantitative RT-PCR for expression analysis.

The quantitative RT-PCR technique was employed to compare the amount of TpPAPI mRNA between mycorrhizal and nonmycorrhizal roots, based on the amount of $18 \mathrm{~S}$ rRNA as an internal standard (Burleigh 2001). Total RNA was extracted and purified as described above, and $1 \mu \mathrm{g}$ of RNA was reverse-transcribed with both the oligo $(\mathrm{dT})_{15}$ primer (3.75 $\mu \mathrm{M})$ for mRNA and the NS21 primer (White et al. 1990) $(1 \mu \mathrm{M})$ for the plant (and fungal) $18 \mathrm{~S}$ rRNA. The cDNA of $18 \mathrm{~S}$ rRNA was amplified with the sense primer NS1 and antisense primer NS21 $(0.2 \mu \mathrm{M}$, respectively), using the 1:20 diluted RT product as a template. The amplification conditions were as follows: initial denaturation at $94^{\circ} \mathrm{C}$ for 2 min, followed by 9 to 21 cycles of $9^{\circ} \mathrm{C}$ for $30 \mathrm{~s}, 50^{\circ} \mathrm{C}$ for 50 $\mathrm{s}$, and $72^{\circ} \mathrm{C}$ for $1 \mathrm{~min}$. The PCR product $(10 \mu \mathrm{l})$ from each cycle were electrophoresed on an agarose gel and were blotted on a nylon membrane with a vacuum blotter (Bio-Rad model 785). The TPPAPl cDNA was amplified with the sense primer $\mathrm{S} 1+$ and antisense primer $\mathrm{D} 2-(0.2 \mu \mathrm{M}$, respectively), using the 1:20 diluted RT product as a template. The amplification conditions were as follows: initial denaturation at $94^{\circ} \mathrm{C}$ for $2 \mathrm{~min}$, followed by 19 to 29 cycles of $94^{\circ} \mathrm{C}$ for 30 $\mathrm{s}, 45^{\circ} \mathrm{C}$ for $50 \mathrm{~s}$, and $72^{\circ} \mathrm{C}$ for $1 \mathrm{~min}$. The PCP products $(10$ $\mu \mathrm{l})$ from each cycle were electrophoresed on an agarose gel, were transferred onto a nylon membrane by a vacuum blotter (Bio-Rad Laboratories). The cDNA fragments of TpPAP1 transcripts and $18 \mathrm{~S}$ rRNA were detected by DIG-labeled probes that were amplified with the primer sets of $\mathrm{S} 1+$ and D2- (for TpPAP1) and the NS1 and NS21 (for 18S rRNA) and were labeled using the DIG high prime DNA labeling and detection kit (Roche Diagnostics) according to the manufacturer's instructions.

Signal intensity of the Southern hybridization was quantified by the NIH Image (National Institutes of Health, Bethesda, MD, U.S.A.). Cycle numbers that corresponded to the linear phase of the PCR reaction were identified on a semilogarithmic plot of signal intensity of the Southern blot versus cycle number of the PCR. The initial amount of the TpPAP1 cDNA and rDNA in each RT product was estimated according to Iwai and associates (1995), and the amount of TpPAPl cDNA was standardized by that of $18 \mathrm{~S}$ rRNA.

\section{Preparation of antiserum and Western blot analysis.}

To raise an antiserum against the $T p P A P 1$ product, the first 20 residues of the N-terminus of the mature protein, D-I-S-AD-M-P-L-N-S-D-V-F-A-L-P-H-G-F-N, were chosen as an immunogen. Bio-Research, Co., Ltd. (Tokyo) synthesized the peptide (YP-337), immunized two rabbits by injecting the immunogen every two weeks over three months, and prepared antisera by standard protocols. Antibody titer of the sera against YP-337 was evaluated by enzyme-linked immunosorbent assay, and a serum showing higher titer was used thereafter.

Crude enzyme solution (soluble protein) was extracted as described at "Electrophoretic analysis of phosphatase." The samples were mixed with the SDS-PAGE sample buffer and were denatured at $95^{\circ} \mathrm{C}$ for $5 \mathrm{~min}$. Protein $(30 \mu \mathrm{g})$ was loaded on a $10 \%$ SDS-polyacrylamide gel and was run at 10 to $20 \mathrm{mV}$ constant current. The proteins were electroblotted onto a nitrocellulose membrane in the transfer buffer $(25 \mathrm{mM}$ Tris, 192 $\mathrm{mM}$ glycine, $10 \%$ methanol) at $80 \mathrm{~V}$ and 800 to $1,000 \mathrm{~mA}$ for $4 \mathrm{~h}$ under ice-cooled conditions. The blot was stored in the transfer buffer at $-20^{\circ} \mathrm{C}$ until use. After transfer, the gel was stained with Coomassie brilliant blue R-250 to evaluate the efficiency of the transfer. Immunodetection was carried out with the ECL Western blotting detection system (Amersham Bioscience, Buckinghamshire, U.K.), according to the manufacturer's instructions.

\section{ACKNOWLEDGMENTS}

We are most grateful to K. Nakamura and A. Morikami for invaluable advice on cloning of the gene. We thank S. Burleigh for his technical advice on the quantitative RT-PCR. This study was supported by the Grantin-Aid for Scientific Research from Japanese Society for the Promotion of Science (T. Ezawa).

\section{LITERATURE CITED}

Aono, T., Maldonado-Mendoza, I. E., Dewbre, G. R., Harrison, M. J., and Saito, M. 2004. Expression of alkaline phosphatase genes in arbuscular mycorrhizas. New Phytol. 162:525-534.

Barrett-Lennard, E. G, Dracup, M., and Greenway, H. 1993. Role of extracellular phosphatases in the phosphorus-nutrition of clover. J. Exp. Bot. 44:1595-1600.

Bieleski, R. L. 1973. Phosphate pools, phosphate transport, and phosphate availability. Ann. Rev. Plant Physiol. 24:225-252.

Boddington, C. L., and Dodd, J. C. 1999. Evidence that differences in phosphate metabolism in mycorrhizas formed by species of Glomus and Gigaspora might be related to their life-cycle strategies. New Phytol. 142:531-538.

Burleigh, S. H. 2001. Relative quantitative RT-PCR to study the expression of plant nutrient transporters in arbuscular mycorrhizas. Plant Sci. 160:899-904

Dakora, F. D., and Phillips, D. A. 2002. Root exudates as mediators of mineral acquisition in low-nutrient environments. Plant Soil 245:35-47.

Dodd, J. C., Burton, C. C., Burns, R. G., and Jeffries, P. 1987. Phosphatase activity associated with the roots and the rhizosphere of plants infected with vesicular-arbuscular mycorrhizal fungi. New Phytol. 107:163-172.

Duff, S. M. G., Sarath, G., and Plaxton, W. C. 1994. The role of acid phosphatases in plant phosphorus metabolism. Physiol Plant. 90:791-800.

Durmus, A., Eicken, C., Spener, F., and Krebs, B. 1999. Cloning and comparative protein modeling of two purple acid phosphatase isozymes from sweet potatoes (Ipomoea batatas). Biochim. Biophys. Acta 1434:202-209.

Ezawa, T., and Yoshida, T. 1994a. Characterization of phosphatase in marigold roots infected with vesicular-arbuscular mycorrhizal fungi. Soil Sci. Plant Nutri. 40:255-264.

Ezawa, T., and Yoshida, T. 1994b. Acid phosphatase specific to arbuscular mycorrhizal infection in marigold and possible role in symbiosis. Soil Sci. Plant Nutri. 40:655-665.

Ezawa, T., Kuwahara, S., Sakamoto, K., Yoshida, T., and Saito, M. 1999. Specific inhibitor and substrate specificity of alkaline phosphatase expressed in the symbiotic phase of the arbuscular mycorrhizal fungus, Glomus etunicatum. Mycologia 91:636-641.

Fries, L. L. M., Pacovsky, R. S., Safir, G. R., and Kaminski, J. 1998. Phosphorus effect on phosphatase activity in endomycorrhizal maize. Physiol. Plant. 103:162-171.

Gianinazzi-Pearson, V., and Gianinazzi, S. 1976. Enzymatic studies on the metabolism of vesicular-arbuscular mycorrhiza. I. Effect of mycorrhiza formation and phosphorus nutrition on soluble phosphatase activities in onion roots. Physiol. Vég. 14:833-841.

Gianinazzi, S., Gianinazzi-Pearson, V., and Dexheimer, J. 1979. Enzymatic studies on the metabolism of vesicular-arbuscular mycorrhiza. III. Ultrastructural localization of acid and alkaline phosphatase in onion roots infected by Glomus mosseae (Nicol. \& Gerd.). New Phytol. 82:127-132.

Haran, S., Logendra, S., Seskar, M., Bratanova, M., and Raskin, I. 2000 Characterization of Arabidopsis acid phosphatase promoter and regulation of acid phosphatase expression. Plant Physiol. 124:615-626.

Harrison, M. J. 1996. A sugar transporter from Medicago truncatula: Altered expression pattern in roots during vesicular-arbuscular (VA) mycorrhizal associations. Plant J. 9:491-503.

Iwai, M., Kanzaki, H., Fujimoto, M., Kojima, K., Hatayama, H., Inoue, T., Higuchi, T., Nakayama, H., Mori, T., and Fujita, J. 1995. Regulation of sex steroid receptor gene expression by progesterone and testosterone in cultured human endometrial stromal cells. J. Clin. Endocrinol. Metab. 80:450-454.

Joner, E. J, and Johansen, A. 2000. Phosphatase activity of external hyphae of two arbuscular mycorrhizal fungi. Mycol. Res. 104:81-86.

Kaida, R., Sage-Ono, K., Kamada, H., Okuyama, H., Syono, K., and Kaneko, T. 2003. Isolation and characterization of four cell wall purple acid phosphatase genes from tobacco cells. Biochim. Biophys. Acta 1625:134-140.

Klabunde, T., Sträter, N., Fröhlich, R., Witzel, H., and Krebs, B. 1996. Mechanism of $\mathrm{Fe}(\mathrm{III})-\mathrm{Zn}$ (II) purple acid phosphatase based on crystal structures. J. Mol. Biol. 259:737-748.

Li, D., Zhu, H., Liu, K., Liu, X., Leggewie, G., Udvardi, M., and Wang, D. 
2002. Purple acid phosphatases of Arabidopsis thaliana. Comparative analysis and differential regulation by phosphate deprivation. J. Biol. Chem. 277:27772-27781.

Liu, H., Trieu, A. T., Blaylock, L. A., and Harrison, M. J. 1998. Cloning and characterization of two phosphate transporters from Medicago truncatula roots: Regulation in response to phosphate and to colonization by arbuscular mycorrhizal (AM) fungi. Mol. Plant-Microbe Interact. 11:14-22.

Miller, S. S., Liu, J., Allan, D. L., Menzhuber, C. J., Fedorova, M., and Vance, C. P. 2001. Molecular control of acid phosphatase secretion into the rhizosphere of proteoid roots from phosphorus-stressed white lupin. Plant Physiol. 127:594-606.

Nishikoori, M., Washio, K., Hase, A., Morita, N., and Okuyama, H. 2001. Cloning and characterization of cDNA of the GPI-anchored purple acid phosphatase and its root tissue distribution in Spirodela oligorrhiza. Physiol. Plant. 113:241-248.

Ryan, P. R, Delhaize, E., and Jones, D. L. 2001. Function and mechanism of organic anion exudation from plant roots. Ann. Rev. Plant Physiol. Plant Mol. Biol. 52:527-560.

Scandalios, J.G. 1969. Genetic control of multiple molecular forms of enzymes in plants: A review. Biochem. Genet. 3:37-79.

Schachtman, D. P., Reid, R. J., and Ayling, S. M. 1998. Phosphorus uptake by plants: From soil to cell. Plant Physiol. 116:447-453.

Schenk, G., Guddat, L. W., Ge, Y., Carrington, L. E., Hume, D. A., Hamilton, S., and de Jersey, J. 2000. Identification of mammalian-like purple acid phosphatases in a wide range of plants. Gene 250:117-125.

Smith, F. W. 2002. The phosphate uptake mechanism. Plant Soil 245:105114
Smith, F. A, Jakobsen, I., and Smith, S. E. 2000. Spatial differences in acquisition of soil phosphate between two arbuscular mycorrhizal fungi in symbiosis with Medicago truncatula. New Phytol. 147:357366.

Sträter, N., Klabunde, T., Tucker, P., Witzel, H., and Krebs, B. 1995. Crystal structure of a purple acid phosphatase containing a dinuclear Fe(III)$\mathrm{Zn}$ (II) active site. Science 268:1489-1492.

Tarafdar, J. C., and Marschner, H. 1994. Phosphatase activity in the rhizosphere and hyphosphere of VA mycorrhizal wheat supplied with inorganic and organic phosphorus. Soil Biol. Biochem. 26:387-395.

Tisserant, B., Gianinazzi-Pearson, V., Gianinazzi, S., and Gollotte, A. 1993. In planta histochemical staining of fungal alkaline phosphatase activity for analysis of efficient arbuscular mycorrhizal infections. Mycol. Res. 97:245-250.

Wasaki, J, Omura, M, Osaki, M, Ito, H, Matsui, H, Shinano, T, and Tadano, T. 1999. Structure of a cDNA for an acid phosphatase from phosphate-deficient lupin (Lupinus albus L.) roots. Soil Sci. Plant Nutri. 45:439-450.

Watt, M., and Evans, J. R. 1999. Proteoid roots. Physiology and development. Plant Physiol. 121:317-323.

White, T. J., Bruns, T., Lee, S., and Taylor, J. 1990. Amplification and direct sequencing of fungal ribosomal RNA genes for phylogenetics. Pages 315-322 in: PCR Protocols: A Guide to Methods and Applications. M. A. Innis, D. H. Gelfand, J. J. Sninsky, and T. J. White, eds. Academic Press, San Diego, CA, U.S.A.

Williamson, L. C., Ribrioux, S. P., Fitter, A. H., and Leyser, H. M. 2001. Phosphate availability regulates root system architecture in Arabidopsis. Plant Physiol. 126:875-82. 